\title{
Aliança estratégica no canal de marketing: o caso ALE Combustiveis S.A.
}

\author{
Carlos Eduardo Garcia Cotta ${ }^{\mathrm{a}, *}$, Edson José Dalto ${ }^{\mathrm{b}}$ \\ a,**carlos.cotta@ale.com.br, IBMEC/RJ, Brasil \\ bedalto@ibmecrj.br, IBMEC/RJ, Brasil
}

\begin{abstract}
Resumo
0 artigo analisa a estratégia utilizada pela ALE Combustíveis em uma operação desenhada para vender lubrificantes automotivos em sua rede de postos. 0 estudo avalia as alianças efetuadas com a Elf e posteriormente com a AC Delco, revelando as motivações, escolha dos parceiros, desenho do modelo de relacionamento, gestão das alianças e avaliação do modelo adotado, confrontando a experiência prática com as prescrições da literatura. 0 modelo adotado, denominado broker, caracteriza-se pela preservação da autonomia das marcas, com a ALE aportando sua estrutura e força de vendas, e o parceiro, a logística de reabastecimento e processamento de pedidos. 0 método do caso foi adotado como estratégia de pesquisa e o relato revela o acerto na escolha do modelo, porém falhas estratégicas na capacidade operacional e posicionamento do produto, na aliança com a Elf, e na relação de forças no canal, na aliança com a AC Delco, conduziram ao fracasso de ambas as tentativas.
\end{abstract}

Palavras-chave

Aliança estratégica. Canais de marketing. Gerenciamento de alianças. Lubrificantes.

\section{Introdução}

No Brasil, ao contrário da exploração, produção e refino, a distribuição e revenda varejista nunca estiveram sujeitas ao monopólio estatal. Porém, até 1997, dependiam de regulamentação do Departamento Nacional de Combustíveis (DNC), que determinava os preços de compra e venda. Com o objetivo de dinamizar esse setor, a regulamentação começou a ser flexibilizada a partir de 1992.

Em 1997, quando apenas a Petrobras (BR), Ipiranga, Shell, Esso e Texaco atuavam no mercado, o governo autorizou os postos de combustíveis a se manterem vinculados a uma distribuidora ou atuarem de forma independente, como "bandeira branca". lsto permitiu a entrada de pequenas redes de postos, abrindo espaço para a criação de distribuidoras menores e ampliando a concorrência.

Com o processo de liberalização, a estrutura do mercado sofreu profundas modificações. Em 1998 as grandes distribuidoras passaram a controlar 83\% das vendas, sendo que em 2002 essa parcela havia recuado para $70 \%$. 0 número de distribuidoras cresceu rapidamente, passando de $67 \mathrm{em} 1997$ para 243 em 2003 (REVISTA DE COMBUSTÍVEIS, 2006).
No mercado varejista, verificou-se o aumento de postos com bandeira branca, que em 2003 somavam 12.022 de um total de 43.189. Com isso, a participação de postos das cinco maiores empresas caiu para 72,2\% naquele ano (REVISTA DE COMBUSTIVEEIS, 2006).

Inserido nesse contexto, o mercado de lubrificantes automotivos movimenta anualmente 606 milhões de litros. As cinco tradicionais distribuidoras de petróleo e maiores empresas do país possuem 77\% do mercado (SINDILUB, 2006). Todas com fabricação própria, apresentando embalagens modernas e atraentes e produtos com formulação aprovada por institutos internacionais e montadoras de veículos. Normalmente comercializam seus produtos diretamente para clientes contratados (postos e consumidores finais indústrias, transportadores, empresas de ônibus etc.) e através de distribuidores. Estes têm como objetivo alcançar outros segmentos, como supertroca (lojas especializadas no serviço de troca de óleo), oficinas mecânicas, supermercados e consumidores finais não contratados. 
Outras três marcas internacionais atuam no mercado, porém sem ter rede de postos própria. Essa carência dificulta a visibilidade de suas marcas, bem como a penetração de seus produtos nesse canal de vendas, que é o mais importante. A mais antiga e tradicional no mercado é a Castrol, multinacional inglesa fundada em 1957 e com uma participação de mercado de 7\%. As outras duas são a francesa Elf e a americana FL (Tutela) com participação conjunta inferior a 5\%. As demais empresas, com participações menores, somadas representam apenas 11\% do total (SINDILUB, 2006).

Embora considere o segmento de lubrificantes estratégico, por completar um importante mix de produtos para a empresa, a ALE não contempla em seu planejamento estratégico construir uma fábrica ou mesmo operar com uma linha de produtos com marca própria. Essa decisão significaria aportar vultosos recursos (estimam-se 10 milhões de reais no primeiro ano) no desenvolvimento de formulação, embalagens, aprovação em institutos e construção de marca. Da sua carteira de clientes, estima-se que o potencial é de $200 \mathrm{mil}$ 1/mês em termos de volume de vendas, representando aproximadamente um faturamento de R\$ 1,2 milhão.

Em consequência desse potencial de vendas e de sua carteira de clientes, a ALE vem atraindo empresas fabricantes multinacionais e nacionais que não participam do mercado de postos de revenda. Diante dessa situação, a empresa optou por operar de maneira inédita no mercado de lubrificantes no Brasil, através de um acordo comercial de representação, que lhe dá exclusividade na venda dos produtos para os clientes de sua carteira. Constituiu-se então um novo modelo de aliança estratégica no mercado de lubrificantes. 0 caso a ser apresentado aborda as experiências da ALE neste modelo.

0 objetivo deste artigo é analisar os motivadores, o modelo de aliança estratégica adotado pela ALE e o relacionamento com a Elf e AC Delco como parceiros no canal de distribuição.

O estudo abrange a teoria e a prática da formação de alianças estratégicas no canal de marketing, com foco na experiência da ALE no mercado de lubrificantes, não abordando a comercialização de outros produtos da indústria do petróleo.

0 trabalho está organizado em seis partes. A primeira, já mostrada, apresenta o tema, sua importância, o objetivo da pesquisa, seu escopo e estrutura. A segunda traz a revisão de literatura concentrando-se nos temas de formação de alianças estratégicas e análise de canais de distribuição. A terceira parte revela a metodologia da pesquisa.
A quarta apresenta as alianças formadas pela ALE com a Elf e depois com a AC Delco. A quinta parte analisa as alianças formadas à luz da literatura apresentada. Finalmente a sexta parte dedica-se às considerações finais

\section{Referencial teórico}

Nesta seção do trabalho são apresentados os fundamentos teóricos da motivação da formação de alianças estratégicas, condições para o sucesso, benefícios, riscos, fases da evolução e a tipologia das alianças. A seguir, na seção 2.2, conceituam-se canais de distribuição, a diferenciação entre canais de marketing e de logística, o conceito de logística integrada e nível de serviço nos canais.

\subsection{Alianças estratégicas}

A chave do sucesso para uma aliança sólida é a escolha do parceiro certo. Quando há objetivos estratégicos convergentes, princípios corporativos semelhantes, necessidades e capacidades complementares, e espírito de cooperação, a chance de sucesso é grande. Rosenbloom (2002) considera que uma aliança estratégica deve possuir os seguintes atributos: confiança, segurança, responsabilidade e habilidades pessoais dos envolvidos, que levam ao estabelecimento de metas mutuamente benéficas.

Entretanto, o mercado também traz muitos exemplos de alianças mal-sucedidas. Nesse sentido, Bowersox e Closs (2001) levantam alguns motivos pelos quais as alianças fracassam: metas imprecisas, nível inadequado de confiança, promessas infundadas de nível de serviço, incompatibilidade no relacionamento, estrutura operacional fraca e mensuração inadequada.

Outros aspectos levantados por Hitt, lreland e Hoskinsson (2002) e que precisam ser analisados são: falsificação de competências, contratosinadequados, habilidades administrativas ineficientes e diferenças de estilo administrativo.

Para que a parceria seja efetiva e funcione a contento, todas as partes devem abrir mão de vantagens unilaterais de maneira que o relacionamento se desenvolva. Focar recursos na aliança e renunciar aos lucros no início fazem parte dos sacrifícios envolvidos, inerentes a parcerias de sucesso (COUGHLAN et al., 2002). Mas, para que a relação de confiança se solidifique, é condição necessária o retorno financeiro esperado. Não há como construir uma relação forte sem que os parceiros atinjam seus objetivos econômicos. 
Segundo Coughlan et al. (2002), a estabilidade do fornecedor, corte de custos, diferenciação no mercado e vantagem competitiva duradoura são motivos que conduzem e promovem as parcerias estratégicas entre produtores e distribuidores. Da parte do produtor, é importante que o distribuidor seja um parceiro que ajude a diferenciar sua marca, especialmente em mercados em que o fator crítico de sucesso não é a propaganda, mas a atuação e os serviços do distribuidor. Pelo lado do distribuidor as vantagens também podem ser relevantes. Para Siguaw, Simpson e Baker (1998), distribuidores que são orientados ao mercado tendem a conseguir ganhos consideráveis em seu desempenho financeiro. Nesse sentido, as parcerias ganha-ganha são mais promissoras, na medida em que produtores e distribuidores estão focados direta e indiretamente no aumento das vendas.

Segundo Dwyer, Schurr e Oh (1987), as parcerias estratégicas passam por cinco fases importantes, desde seu estabelecimento até seu encerramento: Conscientização (ou amadurecimento); Exploração (fase de testes); Expansão (aumento dos benefícios); Compromisso (investimento na criação e manutenção do compromisso); e Declínio (insatisfação de um ou de ambos os lados).

Ao abordar a questão do interesse de fazer com que todo relacionamento venha a constituir uma aliança estratégica, Coughlan et al. (2002) postulam que o custo e a dificuldade de desenvolver alianças proveitosas - além da ausência de garantias de sucesso na relação - impõem grande necessidade de avaliação da relação.

Hitt, Ireland e Hoskinsson (2002) apresentam dois níveis de aliança estratégica:

- Nível de unidades de negócio - Inclui as alianças complementares, alianças para redução da competição, alianças de resposta à competição e alianças para redução de incerteza;

- Nível corporativo - Inclui as alianças de diversificação, alianças sinergéticas e franchising.

Dentro do escopo da pesquisa, estaremos abordando principalmente as alianças complementares, para a qual os autores trazem a seguinte definição:

Alianças estratégicas complementares são projetadas para tirar proveito de oportunidades de mercado combinando os ativos da firma sócia de uma forma complementar para criar valor. Alianças horizontais e verticais são os dois tipos de alianças complementares (HITT; IRELAND; HOSKINSSON, 2002, p. 369).

Alianças complementares horizontais são formadas por empresas que atuam no mesmo nível da cadeia produtiva, sendo que estas concordam em compartilhar seus recursos e conhecimentos para o desenvolvimento e comercialização de produtos e serviços. Um exemplo clássico desse tipo de aliança é o setor da aviação internacional que compartilha, por exemplo, os serviços de manutenção, atendimento ao público, bagagens e outros. Na aliança do tipo vertical, as empresas parceiras encontram-se em diferentes etapas da cadeia de valor.

Segundo Tavares (2002), dois terços das maiores empresas líderes no Brasil estabelecem alianças estratégicas buscando principalmente compartilhamento de recursos, competências complementares e redução de custos. Sua pesquisa relatou ainda que um terço das maiores empresas líderes trabalha em redes estratégicas, sendo que percebem que essas alianças influenciam seu desempenho e mudam a natureza da competição. Por outro lado, a parceria traz como risco inerente o desenvolvimento de um processo de interdependência, que pode ser desvantajoso para um dos lados no futuro.

\subsection{Canais de distribuição}

Canais de distribuição estruturam a rede de comércio, através dos quais fluem os produtos manufaturados. Caracterizam-se pelo conjunto de entidades que compõem um caminho de acesso dos bens ou serviços aos consumidores. Com maior rigor, Kotler (2003) define canal de distribuição como o conjunto de organizações interdependentes envolvidas no processo de oferecimento de um produto ou serviço para uso ou consumo de um cliente final ou usuário empresarial. Intermediários são utilizados em grande parte, devido à maior eficiência provida, quando o serviço de distribuição é executado. Em função da rede de contatos, especialização e a escala operacional obtida, decorrem ganhos à indústria quando comparados com a realização das tarefas diretamente.

De acordo com Bowersox e Closs (2001), existe uma diferença conceitual entre canais de marketing e de logística, que constituem os canais de distribuição. Canais de marketing são compostos por empresas que estão voltadas para as transações de compra e venda. Já os canais de logística são constituídos por empresas que administram os níveis e a movimentação dos estoques. Enquanto o canal de marketing opera a transferência de propriedade dos bens entre os elos, a logistica se concentra apenas no fluxo de produtos. 0 fato de ocorrerem em paralelo significa que não pode existir uma eficiente gestão de canal sem uma logística também eficiente (BOWERSOX; CLOSS, 2001). 
A administração moderna de logística procura tratar os seus elos (manuseio de mercadorias, transporte, controle de estoque, armazenamento, processamento de pedidos e embalagem) através do conceito de sistemas, constituindo o que se denomina de logística integrada (BOWERSOX; CLOSS, 2001).

As empresas investem em um projeto logístico para assegurar que seus produtos e serviços cheguem ao cliente no momento certo, na quantidade exata, no sortimento almejado, e a um menor custo. Por isso, cada vez mais se valoriza a pontualidade, a informação sobre os pedidos, a disponibilidade da mercadoria e outros aspectos que se tornaram diferenciais no mundo globalizado e de grande concorrência (FLEURY; WANKE; FIGUEIREDO, 2000).

Segundo Hijjar et al. (2003), fica cada vez mais evidente que os fornecedores precisam adequar sua forma de trabalho às exigências dos varejistas, de modo a proporcionar um serviço melhor ao consumidor. Evidentemente, os níveis de exigência e os atributos a serem avaliados dependem do tipo de serviço e do mercado onde as empresas estão inseridas.

Mesmo que uma empresa possa desempenhar satisfatoriamente as duas atividades, a tendência é que se estruturem separadamente os serviços de marketing e os de logística. Embora relacionados entre si, os fatores que afetam o desempenho de um podem ter efeito contrário no outro (BOWERSOX; CLOSS, 2001).

\section{Metodologia}

0 presente trabalho utiliza o método do estudo de caso, baseado nos seguintes argumentos apresentados por Yin (2004):

- A pergunta central que orienta este estudo é do tipo "como";

- 0 autor da pesquisa não possui o controle sobre os acontecimentos;

- 0 foco da pesquisa está calcado em um fato recente ocorrido na vida real.

0 método do estudo de caso fundamenta-se na teoria de estruturação e construção, que procura avaliar e explicar com mais profundidade fenômenos complexos da vida real. 0 objetivo é trazer para o meio acadêmico e empresarial novos conhecimentos através de observações e interpretações holísticas (RIEGES, 2003; REMENYl et al., 1998).

Eisenhardt (1989) argumenta que os estudos de casos constituem-se importantes fontes de construção teórica, sendo uma de suas principais forças a justaposição de proposições contraditórias ou paradoxais, obrigando o pesquisador a descongelar seu pensamento, buscando nas evidências factuais argumentos para sustentar uma explicação coerente, diferentemente das teorias incrementais. No entanto, a mesma autora adverte para dois problemas na utilização dessa metodologia, que são a falta de parcimônia e a idiossincrasia da teoria. Ambos decorrem da profusão e riqueza de dados levantados, que sugerem ao pesquisador valer-se de grande parte deles na construção teórica, o que dificulta a generalização.

De acordo com Yin (2004), para efetuar a pesquisa com confiabilidade e dar melhor orientação no processo, o pesquisador deve observar três princípios para assegurar a validade de construto e a confiabilidade do estudo:

- Utilizar várias fontes de evidência, valendo-se da triangulação;

- Criar um banco de dados para o estudo de caso;

- Manter o encadeamento das evidências, na perspectiva de um observador externo.

Seguindo essa proposta que ressalta a importância do uso da triangulação de fontes diversas para gerar conclusões mais sólidas, foram coletados dados pelos seguintes meios:

- Fonte secundária, através do estudo e análise de documentos para "corroborar e valorizar as evidências oriundas de outras fontes" (YIN, 2004). Os documentos foram disponibilizados pela empresa, sendo, em sua maioria, dados publicados;

- Observação participante, realizada por um dos autores do trabalho, na condição de diretor comercial e coparticipante do processo das alianças estratégicas.

- Entrevistas semiestruturadas em profundidade com os principais executivos da ALE e de seus parceiros para obter suas impressões em relação a diversos fatores das alianças.

Os entrevistados e respectivas identificações dividem-se na pesquisa entre:

- ALE: Presidente (E1), Diretor de Logística (E2) e Gerente de Lubrificantes (E3);

- Elf: Gerente de Lubrificantes (E4);

- AC Delco: Gerente de Projeto de Lubrificantes (E5) e Assessor da Linha de Lubrificantes (E6).

A etapa de entrevistas realizou-se no período de 14 de setembro a 5 de outubro de 2006.

A pesquisa foi estruturada de acordo com os seguintes tópicos: criação do modelo, definição da estratégia de aliança e seus elementos, gestão da aliança e avaliação do modelo. 


\section{Apresentação do caso ALE Combustiveis S.A.}

A ALE Combustíveis S.A. foi fundada em 1996, com capital nacional privado. Atua no negócio de distribuição de combustíveis no Brasil, que se caracteriza por margens baixas e, portanto, escala é fundamental. Nesse sentido, todo o esforço da ALE, desde sua fundação, concentrou-se em aumentar sua cadeia de postos, o que demandou elevados investimentos em imagem e capital de giro, além de construção de bases de armazenagem de derivados.

Sua estrutura de capital não comportava, portanto, investimentos em fábrica de lubrificantes e desenvolvimento de uma linha de produtos com embalagens, certificações de montadoras de veículos, formulação de produtos, desenvolvimento de marca e contratação de pessoal especializado. Por outro lado, não participar do mercado de lubrificantes significava operar com um mix de produtos incompletos, ao mesmo tempo que enfraquecia sua relação comercial com seus revendedores, pois, ao abrir espaço para os concorrentes, a ALE estaria declinando de uma receita importante.

Seu dilema consistia em controlar uma importante fatia do principal canal de distribuição de lubrificantes, sua cadeia de postos, e não ter acesso ao produto. Como havia no mercado empresas com posição inversa, ou seja, produtoras de lubrificantes e sem a participação no principal canal de distribuição, estava identificado aí um potencial de aliança. 0 modelo desenhado pela ALE, em função de sua carteira de clientes e pela atratividade exercida nos fabricantes de lubrificantes com marca forte, sem uma rede de postos, foi o de broker. 0 modelo permitia aos parceiros atuar cooperativamente dentro do escopo da aliança, preservando os direitos de propriedade das respectivas marcas. Atribuía-se à ALE a responsabilidade de agenciar os pedidos junto aos consumidores, através de sua força de vendas, enquanto o fornecedor arcava com o estoque, gerenciamento do crédito, faturamento e logística.

Inicialmente foram prospectadas as empresas Castrol, Tutela e Elf. Todas com marcas reconhecidamente fortes no mercado nacional e internacional, com produção própria, formulações aprovadas nas principais montadoras de veículos leves e pesados, ampla linha de lubrificantes e graxas, inclusive no segmento industrial.

\subsection{Aliança com a Elf}

Tendo sido visitadas a Castrol, Tutela e Elf, a melhor proposta apresentada foi a da Elf. Marca internacionalmente conhecida, principal patrocinadora do Rally Paris-Dacar, presente na
Fórmula 1 e principal fornecedora das marcas Renault e Citröen. Dispunha de uma linha completa de produtos e lubrificantes de última geração, fábrica própria em São Paulo, além de embalagens modernas e atraentes. A proposta aprovada foi que a ALE receberia $20 \%$ da receita líquida (receita bruta - impostos) das vendas efetivamente faturadas e pagas. Receberia ainda R\$ 160 mil pelo "direito de passagem" (fee), por um contrato de três anos e/ou 4 milhões de litros vendidos. A Elf ficaria responsável pelos materiais promocionais e dos pontos de vendas (displays, folhetos e etiquetas de lubrificação).

Esse modelo inovador apresentou, no entanto, três problemas graves que prejudicaram sobremaneira o relacionamento entre os parceiros: a divergência de foco, a distribuição e a liquidação financeira.

Em 2004 o mercado de lubrificantes estava bastante acirrado e a Elf concentrava seus esforços na linha premium, de preços mais elevados, pois obtinha maior lucratividade. Os postos da ALE localizavam-se em cidades do interior ou periferia dos grandes centros, nos estados de Minas Gerias, Rio de Janeiro, Goiás, Distrito Federal, Espírito Santo, São Paulo, Paraná e Bahia. Seu perfil estava, portanto, voltado para lubrificantes da linha de "combate", de qualidade inferior e preços mais baixos.

As vendas da Elf eram focalizadas nas concessionárias Renault e Citröen - fruto de um acordo internacional - e em alguns distribuidores e, portanto, demandavam uma logística muito simples e concentrada em grandes centros urbanos. 0 perfil das vendas da ALE era muito mais fracionado. Consequentemente, o sistema de entrega não funcionou. A fábrica não conseguia entregar de modo eficiente as quantidades solicitadas. Havia um compromisso de prazos máximos de até quatro dias para entrega na capital e até oito dias no interior, que não foram cumpridos. Estes atrasos geraram desgaste e afetaram o desempenho das vendas. $\mathrm{Na}$ análise da capacidade do fornecedor, esse fator (logística) foi superficialmente analisado por ambas as empresas. 0 problema foi solucionado depois de muitos atritos, através da contratação de um operador logístico.

Outro ponto de desgaste foi a liquidação financeira dos pagamentos. 0 volume de notas fiscais e faturamento da Elf eram menores em função do número de transações com as concessionárias e distribuidores. 0 volume de transações com os postos ALE aumentou consideravelmente e a estrutura da Elf não estava preparada para fazer a liquidação para uma carteira de clientes quase 50 vezes maior. Passou de uma venda de atacado para uma venda 
Tabela 1. Vendas de lubrificantes Elf.

\begin{tabular}{cc}
\hline Período & Volume (litros) \\
\hline Jun. 01/Dez. 01 & 95.158 \\
Jan. 02/Dez. 02 & 280.337 \\
Jan. 03/Dez. 03 & 652.803 \\
Jan. 04/Ago. 04 & 304.875 \\
Total vendido & 1.333 .173 \\
\hline
\end{tabular}

Fonte: ALE Combustíveis S.A.

de varejo. Mais uma vez houve erro de avaliação quanto à capacidade do fornecedor de administrar o volume do faturamento.

Na Tabela 1 é apresentada a evolução das vendas nos três anos de vigência do contrato.

Embora a ALE tenha vendido apenas 33\% do volume, o contrato se encerrou depois de decorridos os três anos compromissados. No final deste período, a logística e o faturamento estavam funcionando em níveis razoáveis de controle.

Além disso, um importante segmento em que a ALE atua é o de consumidor final, que consiste nas vendas diretas para transportadoras, pequenas e médias indústrias, empresas de transportes urbanos, grandes fazendas e pesca. Para a AlE é uma participação estratégica. Este segmento demanda uma linha especial de lubrificantes e possui um potencial elevado de consumo. Como se utilizam de máquinas caras e fundamentais para o funcionamento do negócio, a questão da lubrificação (manutenção) passa a ter um caráter fundamental. A linha da Elf nesse segmento não era completa. Sua fábrica está voltada principalmente para lubrificantes da linha leve. Sua estratégia para esse segmento apoiava-se na possibilidade de importar de outras fábricas espalhadas pelo mundo, o que na prática não funciona, pois o segmento demanda um suprimento regular, com preços competitivos e disponibilidade imediata, caso algum problema com o maquinário venha a ocorrer.

\subsection{Aliança com a AC Delco}

Essa situação com a frustração dos volumes vendidos abriu espaço para uma negociação inédita. A primeira parceria entre uma montadora de automóveis e uma distribuidora de petróleo. A AC Delco, braço da General Motors, oferecia uma proposta para a ALE extremamente competitiva e atraente. Como todos os produtos que vende, o lubrificante era produzido por terceiros (BR) e levava a marca AC Delco.

Além de se associar a uma marca forte como a GM, a ALE teria as seguintes vantagens no contrato:

1 Os produtos da AC Delco seriam 10\% mais baratos que os similares da Elf;
2 Receberia a mesma comissão de $20 \%$ sobre a receita líquida;

3 Estavam sendo disponibilizados uma linha extensa de acessórios e outros produtos da linha automotiva da AC Delco (baterias, palhetas, filtros, produtos químicos etc.);

4 Direito de passagem (fee) de $\mathrm{R} \$ 200 \mathrm{mil} / \mathrm{ano}$, por um contrato de três anos, sem compromisso de volume;

5 Campanha de lançamento voltada para os clientes ALE totalmente custeada pela AC Delco;

6 Enxoval para os postos ALE com expositores, coletes para frentista, pôsteres, tabelas e material promocional.

Antes de assinar o contrato, foi feita uma avaliação detalhada do fornecedor, particularmente sobre os pontos críticos do contrato anterior, como a logística de entrega e o faturamento. Nesse caso, a AC Delco já possuía uma estrutura de varejo e faturava e entregava de forma muito mais fragmentada que a própria ALE. A marca aparentemente não foi um problema, pois a $A C$ Delco, embora não tenha tradição em lubrificantes, é muito forte na área de autopeças e carrega a tradição e a força da marca GM.

No primeiro ano de relacionamento, após um período inicial de adaptação, o desempenho da parceria avançava como esperado. 0 crescimento das vendas seguia conforme planejado, havia boa aceitação por parte da revenda e dos consumidores dos produtos, a equipe de vendas trabalhava nos investimentos no ponto de venda e a oferta de acessórios da AC Delco foi um diferencial e nova fonte de receita para os revendedores ALE. Todos os compromissos assumidos em contrato estavam sendo cumpridos, o que deixava a relação mais forte. A ALE ficou bastante satisfeita com a divulgação da parceria e a associação de sua marca com a GM.

Após um ano de convivência, a AC Delco procurou a ALE para explicar que não seria mais possível cumprir o contrato, pois sua fornecedora, a BR Distribuidora, não tinha mais interesse em continuar suprindo-a. Na verdade, a BR estava interessada em ser fornecedora da GM em combustíveis e aceitou fornecer lubrificantes para a AC Delco visando aquele produto. Como a GM fez uma concorrência e a Texaco saiu vencedora, fechando contrato por dois anos com a montadora, a BR "perdeu o interesse" e simplesmente cortou o fornecimento de lubrificantes para a AC Delco. A Texaco, além de abastecer a montadora com combustíveis, fornece lubrificantes para a GM (concessionárias) e não tem interesse e nem o compromisso de fornecer para a AC Delco. Para credenciar outro fornecedor na AC Delco, o processo demoraria pelo menos dois anos 
para homologações e aprovações internamente. A ALE não poderia esperar este tempo. Estava assim comprometido o que seria um grande negócio para a ALE.

Para evitar uma demanda judicial, acabaram fazendo um acordo. Hoje a ALE está no mercado procurando alternativas. Ainda sofre desgaste com sua carteira de clientes e a perda de receita, pois, além de não oferecer uma linha de lubrificantes, abriu espaço para os concorrentes ocuparem as prateleiras de seus postos.

\section{Apresentação e análise dos resultados}

Este item compõe-se da apresentação dos resultados e análise do processo de aliança estratégica da ALE com a Elf e, posteriormente, com a AC Delco. Lembra-se que o objetivo principal da pesquisa é analisar os motivos que levaram à formação das alianças, o modelo adotado e sua gestão, relacionando o comportamento e as decisões tomadas pelos executivos durante o processo com a literatura pertinente ao tema. Os resultados são organizados em quatro tópicos: motivadores para a formação de aliança, modelo de aliança estratégica, gestão das alianças e avaliação do modelo. Nessa etapa são utilizadas principalmente as fontes de evidências citadas na metodologia, ou seja, dados secundários, observação participante do diretor comercial e corresponsável pelas alianças e entrevistas com executivos das três empresas envolvidas.

\subsection{Motivadores para a formação de aliança}

Para entender as razões para a criação do modelo por parte da ALE, é necessário inicialmente compreender a necessidade e a importância de uma empresa de distribuição de combustíveis em vender lubrificantes e o surgimento de um ambiente propício ao estabelecimento de uma aliança estratégica nesse segmento.

A distribuição de combustíveis caracteriza-se por ser altamente competitiva e com margens operacionais bastante reduzidas. A venda de lubrificantes passa a ser um complemento fundamental na composição da receita bruta. Também não operar com lubrificantes significa trabalhar com um mix incompleto de produtos. Essa constatação é unânime entre os executivos da ALE entrevistados.

Não ter o controle da venda de lubrificantes nas prateleiras de seus postos pode significar também estar vulnerável à ação de seus concorrentes.
Estes poderão estabelecer uma relação comercial secundária, e tornar-se uma ameaça concreta no futuro.

Outra razão importante para a comercialização de lubrificantes é o relacionamento com o consumidor final, principalmente pelo controle da oferta dos produtos vendidos. Os especialistas entendem que a percepção de qualidade dos produtos ofertados está diretamente relacionada com a identificação da marca e o controle do ponto de venda por parte da distribuidora. A citação a seguir ilustra essa razão:

E3: “... Dentro da expectativa do consumidor, não ter lubrificantes no ponto de venda pode ser considerado como uma oferta incompleta. Se a distribuidora não o tem, ela não exerce controle sobre a oferta..."

Desde a sua fundação, a ALE desenvolveu 450 postos no Brasil com sua bandeira, além de conquistar consumidores corporativos, tais como transportadoras, empresas de ônibus, pequenas indústrias e outros grandes consumidores, o que confere um potencial de vendas de lubrificantes de aproximadamente 200 mil l/mês.

Coughlan et al. (2002) a firmam que um dos pilares para uma aliança estratégica forte é a capacidade do distribuidor em colaborar na diferenciação da marca do produtor. Nesse sentido, a ALE exerce poder sobre a revenda e conta ainda com postos novos, com imagem atraente. 0 depoimento de um executivo da Elf corrobora essa consideração:

E4: “... A principal razão da escolha do parceiro ALE foi o seu compromisso estratégico e ético, que representará a perenidade da empresa para os próximos anos, onde se incluem cuidados com a própria marca e a de seus parceiros, uma rede de pontos de venda estabelecidos e controlados, planos de expansão e ausência de vínculo com os principais players estabelecidos no Brasil..."

Pelo lado dos fabricantes, a oportunidade de encontrar um parceiro com uma carteira de clientes formada era bastante atrativa, principalmente para aqueles que não participavam do mercado de postos (exemplos: Elf, Castrol e FL). A seguir são transcritos comentários que exemplificam esse item:

E4: “.. No caso da Elf, acreditamos que, apesar da nossa presença em concessionárias, por força de contratos mundiais e locais, deixávamos de estabelecer um contato permanente e frequente com o consumidor, se não estivermos presentes nos postos de gasolina, um importante canal para o nosso negócio...".

E5: “... Em princípio, a ALE, pela exposição e cuidados com a marca, além dos seus planos de crescimento, foi identificada como rede de varejo organizada, o que nos pareceu uma oportunidade 
de desenvolver esse canal para vendas de baterias. Com as conversas iniciais vimos que a parceria poderia ser muito mais ampla, envolvendo vários itens de reposição e até serviços. No entanto, para ser considerada uma solução completa para o canal e para o consumidor, era importante incluir a linha de lubrificantes, item importante de faturamento e de imagem no ponto de venda...".

Com esses fatores, foi possível para a ALE desenvolver um modelo que atendesse suas necessidades (melhorar sua receita bruta e ofertar uma linha completa de lubrificantes), buscando produtores interessados em participar de um canal de vendas importante. Dessa forma, estabeleceu-se um projeto de aliança complementar do tipo vertical (HITT; IRELAND; HOSKINSSON, 2002). A ALE, primeiramente com a Elf e posteriormente com a AC Delco, concordou em compartilhar seus recursos, competências, custos e riscos para criar valor para seus acionistas, comercializando lubrificantes através de um modelo broker (HITT; IRELAND; HOSKINSSON, 2002).

\subsection{Modelo de aliança estratégica}

Nesta subseção analisaremos as razões que levaram a ALE a estabelecer alianças estratégicas utilizando o modelo broker e as variáveis que influenciaram na escolha dos parceiros. 0 modelo broker é entendido como a intermediação de forma independente na maioria de suas transações, mas atuando de maneira efetiva nas negociações de compra e venda sem assumir os direitos sobre o produto.

A ALE disponibilizou sua força de vendas e participação no mercado, ampliando o canal de vendas do produtor, mediante a vantagem de comercializar lubrificantes sem grandes investimentos.

Além do pacote financeiro que foi fundamental para concretização das alianças, os principais condicionantes da ALE na escolha de seus parceiros foram:

\subsubsection{Marca forte}

Além da possibilidade de oferecer aos seus revendedores uma linha completa de lubrificantes, a parceria com uma empresa de marca forte possibilitaria a associação da marca ALE, pouco reconhecida pelo consumidor, com outra marca de maior exposição. Os depoimentos dos executivos da ALE confirmam esse anseio:
E2: “... Na aliança com a Elf tivemos a oportunidade de associar a marca ALE com uma multinacional do setor. Na época, por estarmos fornecendo para o Carrefour e por termos as cores azul, branco e vermelho, alguns consumidores passaram até a acreditar que a ALE era francesa. Com a proliferação de pequenas empresas adulteradoras no mercado brasileiro, ser confundida naquele momento com uma empresa internacional até que não foi ruim...".

E1: “... A associação de uma distribuidora de combustiveis com uma montadora de automóveis foi um fato inédito na história do setor. Para nós foi muito importante associar a marca ALE com a GM (AC Delco)...".

\subsubsection{Objetivos complementares}

Essa complementaridade pode ser facilmente destacada no depoimento do executivo da Elf:

E4: “... Aqui no Brasil nosso foco inicial foi atender as montadoras com nossos lubrificantes através dos acordos internacionais. Não tínhamos em nosso planejamento estratégico como formar uma cadeia de postos com a nossa marca. A oportunidade de aliança com a ALE nos permitiu entrar de forma rápida no canal de postos sem maiores investimentos...".

\subsubsection{Envolvimento da alta administração}

Nas entrevistas verificou-se que a participação e o comprometimento das diretorias das empresas nos projetos foram fundamentais para a consolidação das alianças, particularmente no que diz respeito ao alinhamento dos objetivos estratégicos e à aceitação do modelo broker, como ilustram os depoimentos dos executivos da ALE:

E1: “... Quando percebemos que a diretoria da Elf participava do projeto e se envolvia nas questões fundamentais, percebemos que o acordo poderia ir para frente...".

E2: “... Tínhamos o compromisso do presidente da GM no Brasil de que todos os esforços seriam feitos para que a parceria desse certo. A participação direta dele nos dava a garantia do sucesso...".

\subsubsection{Ausência de conflitos no canal de distribuição}

Algumas empresas, embora não participassem diretamente no mercado de postos, possuíam uma rede de representantes trabalhando nesse canal. Certamente esse conflito impediria uma convivência 
sadia e de relação duradoura, conforme a exposição de um executivo da ALE:

E1: “... Outras empresas nos fizeram propostas bastante vantajosas, mas a maioria delas já participava de alguma forma do segmento através de distribuidores independentes. $O$ fato de quererem limitar a nossa atuação para evitar conflitos fez diminuir nosso interesse em uma aliança...".

\subsubsection{Complementaridade de competências}

Aqui entram diversos aspectos, tais como estrutura organizacional, linha de produtos, capacidade de produção, área de atuação e suporte técnico. A seguir são transcritos comentários que exemplificam esse item:

E2: “... O fato de a Elf possuir uma fábrica moderna e estrategicamente bem localizada nos motivou bastante...".

E1: “... Um diferencial foi o treinamento técnico que a Elf ofereceu para os nossos funcionários da equipe comercial...".

E2: “... Quando a AC Delco acenou com a possibilidade de ampliarmos a linha de produtos a serem vendidos, disponibilizando uma variedade de artigos enorme, ficamos realmente entusiasmados...".

E2: “... A AC Delco ofereceu a possibilidade de inovarmos com seu projeto de car care nos postos de gasolina...".

E5: “... A divisão AC Delco já possuía experiência em vários locais no mundo na operação de centros de serviços automotivos, mas essa era uma experiência pioneira em rede de postos de gasolina e principalmente de vendas diretas ao varejo (posto), sem a intermediação de distribuidores...".

\subsection{Gestão das alianças}

Fundamentados na literatura exposta em 2.1, analisamos separadamente as alianças com a Elf e a AC Delco, para identificar as causas dos insucessos, iniciando pelo primeiro caso.

\subsubsection{Estrutura operacional inadequada}

A primeira questão que suscitou conflito foi a avaliação incorreta da capacidade de logística da Elf para o processamento de pedidos e serviço de entrega fracionada e de pequenas quantidades em pontos de venda espalhados pela área de atuação da ALE. A experiência do fornecedor, até então, era entregar de forma concentrada e em grandes quantidades. Até que a questão fosse resolvida com a contratação de um operador logístico, muitos problemas com a revenda tiveram que ser contornados, como observado nos depoimentos a seguir:

E4: “... Primeiro tivemos que preparar o nosso sistema operacional para ter um número muito superior de clientes, comparado com o que tínhamos. Isto envolvia mais controles e serviços correlatos como: aprovação de cadastro/crédito, número de notas fiscais emitidas, boletos de pagamento, cobrança, reconciliação etc. Tivemos problemas de vários tipos pela novidade e pelo volume de transações envolvidas. No que se refere à fabricação, não tivemos problemas, pois o dimensionamento foi adequado à expectativa. No entanto, a logística de entregas se revelou complexa e quase sem controle, quando utilizamos a nossa forma tradicional de compor cargas e rotas, o que nos obrigou a buscar especialização no mercado através de um operador logístico, que melhorou bastante a operação já nos primeiros momentos e conseguiu estabelecer um processo sob controle no decorrer do tempo...".

E2: “... Além do problema do faturamento, passamos a ter relatórios imprecisos por um bom tempo. A sobrecarga de trabalho foi enorme e $o$ nivel de estresse também...".

\subsubsection{Nível inadequado de confiança}

De acordo com as observações e entrevistas realizadas, o nível de confiança entre as parceiras e predisposição para resolver conflitos foi adequado. Não houve registro de qualquer fato que prejudicasse o desenvolvimento do processo, como, por exemplo, reflete o depoimento a seguir:

E1: “... Se não houvesse um clima de colaboração entre os funcionários, o nível de desgaste teria sido muito maior...".

\subsubsection{Objetivos estratégicos divergentes}

Observou-se um ponto que causou muito desgaste, atingindo principalmente as equipes comerciais e os revendedores. Enquanto a ALE se posicionava junto a consumidores que buscavam produtos mais acessíveis, com postos localizados na periferia dos grandes centros e cidades do interior, a Elf concentrava sua produção na linha premium de preços mais elevados. Os seguintes depoimentos caracterizam bem essa divergência de perspectivas:

E1: “... Esta é uma visão distorcida das empresas multinacionais que atuam no mercado brasileiro. Querem sempre impor a política internacional de focar sua produção nos produtos sintéticos e 
semissintéticos de maior lucratividade. Acontece que o mercado brasileiro, pelas características de sua frota de veículos e pelo poder aquisitivo do consumidor, vive outra realidade. A própria revenda da ALE está posicionada para lubrificantes de categoria e preço inferiores. Remar contra a maré foi um erro estratégico...".

E4: “... A linha premium trouxe ganhos significativos para toda a cadeia. Os revendedores e a ALE também tinham lucros maiores com a venda desses produtos. Além disso, boa parte da nossa estrutura de fábrica estava planejada para atender também as montadoras e, portanto, produzindo mais a linha premium...”.

\subsubsection{Metas imprecisas}

A estimativa de vendas imprecisa foi a principal razão para a não renovação do contrato. Pelo fato de a ALE ter atingido apenas 33\% do volume do contrato, a Elf não realizou os investimentos compromissados no ponto de venda. Essa era uma demanda principalmente dos revendedores que tinham o investimento como certo. 0 desgaste foi grande, pois a ALE havia vendido o projeto de aliança contando com esse aporte de capital que seria reinvestido nos postos. A seguir são transcritos comentários que exemplificam esse item:

E3: “... Na realidade, para o único e importante conflito existente, não houve uma solução adequada, em que se deveriam aportar recursos prévios para ter um resultado à frente (investimento). Dessa forma passamos a ter um bom volume de vendas, mas muito aquém do potencial estimado para o negócio...".

E4: “... Como as vendas não vieram, nós ficamos desobrigados de investir. Esperávamos renegociar o contrato e aí sim investir. Infelizmente a ALE não renovou...".

No caso da AC Delco, o problema da ruptura está concentrado em um único aspecto, uma vez que a relação vinha cobrindo todas as expectativas. Vale ressaltar que a experiência com a Elf evitou que se repetissem os erros.

\subsubsection{Erro estratégico na avaliação da relação de forças ao longo do canal}

Embora não mapeado por Bowersox e Closs (2001) e sim por Porter (1979), observou-se que faltou na análise de parceria a avaliação das forças do controle da produção e, consequentemente, do acesso ao produto por parte da AC Delco. A ruptura do relacionamento com a BR e a impossibilidade de se conseguir um novo fornecedor fizeram com que a aliança fosse desfeita. Uma vulnerabilidade não observada no processo de contratação. E um erro fatal que levou ao fim uma aliança promissora e de aspectos mercadológicos muito fortes, como observado no depoimento a seguir:

E1: “... Jogamos todas as nossas fichas nesse projeto. Tinha tudo para dar certo. Dentro do nosso setor era extremamente impactante pela aliança com uma montadora e pelo aspecto inovador. Nossos revendedores aceitaram bem a linha de produtos e estavam na expectativa dos investimentos no ponto de venda. Nós subestimamos o fato de uma concorrente ser a supridora da AC Delco e não avaliamos a relação comercial entre ambas...".

\subsection{Avaliação do modelo}

Na visão dos executivos entrevistados, o modelo broker, utilizado de forma inédita no mercado nacional nesse setor, é perfeitamente adequado para o propósito pretendido, como ilustrado abaixo:

E3: “... A parte da ALE dentro do ciclo do pedido estava restrita a negociá-lo junto ao revendedor, baseado em disponibilidade de estoque, condições comerciais estabelecidas entre as partes e nível de serviço acordado para as entregas. Após a obtenção do pedido (pela ALE), este era enviado ao ponto faturador (parceiro), aprovado pelo mesmo (crédito) e programado para entrega, ficando então a logística dos pedidos sob total responsabilidade do parceiro, que fornecia monitoramento contínuo do processo, sempre se submetendo aos níveis de serviço acordados...".

No entendimento dos executivos, uma das razões do sucesso do modelo foi a elaboração do contrato que estabeleceu regras claras de convivência e definição de responsabilidades, além da disposição dos pares para solucionar conflitos, como mostra o depoimento abaixo:

E3: “... A ALE sentiu-se satisfeita com o modelo adotado, mas insatisfeita com o volume do negócio (escala). Já o parceiro passou a ter seu produto em vários pontos de venda, permitindo maior divulgação da marca...".

\section{Considerações finais}

As entrevistas realizadas com os executivos e especialistas permitiram analisar com mais profundidade a criação de um ambiente favorável para formação de uma aliança estratégica entre a ALE e seus parceiros, dentro do mercado de distribuição de lubrificantes. Na verdade, analisando 
os resultados, puderam se confirmar muitos aspectos estudados na literatura.

Ficou claro que a ALE buscou estabelecer uma aliança com seus fornecedores aproveitando sua capacidade de trabalhar no canal através da sua cadeia de postos já existente e sua penetração em outros segmentos, como postos bandeira branca e consumidores finais. Na verdade ela estaria maximizando sua estrutura de vendas agregando lubrificantes de um fabricante de marca forte.

Para seus parceiros a aliança proporcionaria participar do canal mais importante na venda de lubrificantes, dando a oportunidade de expor seus produtos nas pistas dos postos, sem que houvesse necessidade de maiores investimentos. Nesse ponto, a complementaridade das aspirações ficou bastante evidenciada, e encontramos na literatura que essa é uma das principais razões para o sucesso das alianças. Tanto a ALE como seus parceiros identificaram que poderiam aumentar suas receitas compartilhando competências e dividindo custos e riscos, possibilitando assim a criação de valor para seus acionistas.

0 modelo adotado também foi descrito com detalhes, sendo este muito bem trabalhado pelas empresas. Dada a estrutura montada, o modelo broker se encaixou perfeitamente. Ficou evidente a importância do comprometimento da alta administração na condução do processo. Também podemos observar como foi fundamental tratar com clareza as regras do jogo e formalizá-las no contrato.

Analisando o período de contrato com a Elf podemos notar que o modelo adotado funcionou bem. Embora a experiência tenha demonstrado algumas dificuldades no início de sua implementação, ao longo do tempo estas foram sendo superadas. Ficou claro que essas dificuldades poderiam ter sido evitadas se o processo de avaliação fosse mais bem planejado, e se alguns aspectos, inclusive levantados na literatura, fossem observados. Um exemplo ilustrativo foi a falta de capacidade logística da Elf, citada na pesquisa. Se a ALE e a Elf tivessem discutido mais o assunto, observando as necessidades de uma e as possibilidades de entrega da outra, certamente muitos transtornos não teriam acontecido.

$\mathrm{Na}$ verdade, o rompimento da aliança deveu-se a uma avaliação inadequada do potencial de vendas e, consequentemente, impossibilitando o compromisso da Elf em investir. Mas não foi um problema do modelo broker adotado. 0 modelo funcionou perfeitamente como desenhado. Tanto é verdade que na aliança com a AC Delco ele se repetiu da mesma forma, com o mesmo processo.
Outra constatação foi que a ALE aprendeu com os erros do primeiro contrato. Na aliança com a AC Delco, o relacionamento foi muito mais tranquilo do ponto de vista operacional. 0 fim da aliança deveu-se a um erro de planejamento estratégico: não antever que o fato da AC Delco não ter controle da produção poderia se tornar uma verdadeira ameaça, como realmente aconteceu.

Portanto, o resultado da pesquisa nos leva a entender os motivos que levaram a ALE a adotar o modelo broker e como ele funcionou, como a ALE se relacionou com seus parceiros e o processo de escolha e de ruptura das alianças. Avaliamos que ficou bem estabelecida a relação do caso com a fundamentação teórica apresentada.

Em síntese, a pesquisa revela, tanto no aspecto acadêmico quanto empresarial, que ao avaliar a possibilidade de estabelecimento de parcerias estratégicas complementares na comercialização de bens, os pretendentes devem atentar para a força da marca; complementaridade de objetivos e competências, tanto estratégicos como operacionais; envolvimento da alta administração e ausência de potenciais conflitos na relação. 0 modelo brokerpode ser bastante satisfatório, na medida em que preserva a identidade das marcas, mas devem ser muito bem estabelecidas as obrigações e competências de cada parceiro. Os dois insucessos apresentados ressaltam também a importância de se avaliar o custo de saída de uma relação, muitas vezes negligenciado no projeto de alianças. A má avaliação, tanto dos aspectos estratégicos quanto operacionais, pode comprometer o resultado de parcerias com bom potencial de sucesso.

\section{Referências}

BOWERSOX Jr., D.; ClOSS, D. J. Logística Empresarial: o processo de integração da cadeia de suprimentos. São Paulo: Atlas, 2001.

COUGHLAN, A. T. et al. Canais de Marketing e distribuição. 6 ed. Porto Alegre: Bookman, 2002.

DWYER, F. R.; SCHURR, P. H.; OH, S. Developing buyer-seller relationships. Journal of Marketing, n. 51, p.11-27, Abril 1987.

EISENHARDT, K. M. Building Theories from Case Study Research. Academy of Management Review, v. 14, n. 4, p. 532-550, 1989.

FLEURY, P. F.; WANKE, P.; FlGUEIREDO, K. F. Logística Empresarial: A perspectiva Brasileira. São Paulo: Atlas, 2000.

HIJJAR, M. F. et al. Evolução do desempenho logístico das indústrias de bens de consumo: uma análise sob a perspectiva do varejista. Rio de Janeiro:COPPEAD, UFRJ, 2003. Artigos Centros de Estudos em Logística (CEL).

HITT, M. A.; IRELAND, R. D.; HOSKISSON, R. E. Administração Estratégica. São Paulo: Thomson, 2002. 
KOTLER, P. Princípios de Marketing. 9 ed. São Paulo: Prentice Hall, 2003.

PORTER, M. E. How competitive forces shape strategy. Harvard Business Review, mar. 1979.

REMENYl, D. et al. Doing Research in Business and Management: An Introduction to Process and Method. Sage Publications, 1998.

REVISTA DE COMBUSTÍVEIS. Disponível em: <http://www. revistacombustiveis.com.br>. Acesso em: 5 out. 2006.

RIEGES, A. M. Validity and reliability tests in case study research: A literature review with "hands-on" application for each research phase. Qualitative Market Research, v. 6 , n. 2, p. 75-87, 2003.
ROSENBLOOM, B. Canais de Marketing: uma visão gerencial. São Paulo: Atlas, 2002.

SINDILUB. Disponível em: <http://www.sindilub.org.br>. Acesso em: 24 out. 2006.

SIGUAW, J. A. et al. Effects of supplier orientation on distributor market orientation and the channel relationship: the distributor perspective. Journal of Marketing, v. 62, p. 99-111, jul. 1998.

TAVARES, M. Alianças e redes estratégicas: as tendências nas empresas líderes no Brasil. 2002. Dissertação (Mestrado) - Departamento de Administração/IAG, Pontifícia Universidade Católica, Rio de Janeiro.

YIN, R. K. Estudo de caso: planejamento e métodos. 3 ed. Porto Alegre: Bookman, 2004.

\title{
Strategic alliance in the marketing channel: the Ale Combustíveis S.A. case
}

\begin{abstract}
This paper analyses the strategy adopted by ALE Combustiveis, a Brazilian Company, in an operation designed to sell automotive lubricants at gas stations. This study reviews the alliances made with Elf and later with AC Delco, exposing ALE's motivations, partner selection, design of relationship model, alliance management and assessment of adopted model, confronting practical experience with prescriptions in the published literature. The model, named broker, is characterized by preservation of the brand's autonomy, with ALE contributing its structure and sales force, and its partner, in turn, the fuelling logistics and order processing. The case method was adopted as a research strategy and this report shows how successful the model selection proved, as well as the strategic blunders related to the operational capacity and product positioning, in the alliance with Elf, and in the forces of management interrelations within the channel, in the AC Delco alliance case, leading to failure in both attempts.
\end{abstract}

\section{Keywords}

Strategic alliance. Marketing channels. Alliance management. Lubricants. 